\title{
ENTREPRENEURIAL TEAMS: \\ A CATEGORIZATION AND THEIR \\ LONG-TERM EVOLUTION
}

\section{Jean-Charles Cachon}

School of Commerce and Administration, Laurentian University

\begin{abstract}
Twenty-nine entrepreneurial teams from central Ontario were examined in three aspects: the mechanisms by which they were formed and modified, their social structure and the complementarity of team members were identified: Husband-Wife, Family-related, Partnerings, and Short-term partnerings, each type showing distinctive characteristics in terms of venture creation and team formation.
\end{abstract}

\section{SOMMAIRE}

Vingt-neuf équipes d'entrepreneurs du centre de l'Ontario ont fait l'objet d'une étude sur trois aspects soit, les mécanismes qui ont contribué à leur formation et à leur évolution, leur structure sociale et la complémentarité des membres de l'équipe : mari-femme, membres d'une même famille, sociétés de personnes et participations à court terme, chaque type présentant des caractéristiques distinctes en termes de création d'entreprise et de formation d'équipe.

\section{OBJECTIVES OF THE STUDY}

Kamm et al. (1) (2) have stressed the lack of qualitative research in the area of assembling, and maintaining, successful entrepreneurial teams. They also imply that entrepreneurial team-building may become part of a venture-creation plan by seeking what kind of combination of members may be the most effective. Past research often limits itself to numerical data, neglecting the qualitative aspects of teamwork in the various stages of creating a firm and managing its growth.

The objective of this study was to obtain some insight into various types of experiences undergone by entrepreneurial team members. An attempt to categorize entrepreneurial teams was made. Interpretations and perceptions about team formation from different members were obtained and analysed.

\section{DEFINITIONS}

For the purpose of this study, an entrepreneurial team was defined as a minimum of two persons who jointly start or operate a venture (3) (4) (2); without necessarily working fulltime with that particular business. Silent partners were not considered as team members, as they were not actively involved in the operation of the organization.

A broad definition of the term "entrepreneur" was adopted which, in some cases, included people not directly involved in the creation of the business. The reality of team entrepreneuring involves, in many cases, a small group of founders plus other members joining the team later on.

Success is considered in terms of the persistence of the team, as opposed to economic measures of profitability or growth; the existence of the business after at least two years was considered as a condition to be part of the study. Unsuccessful teams involve situations 
where the business, whilst created by a team, has become a sole owner-managership by the time of the interview. The design of this project did not allow the identification of teams failing by going out of business or being more or less successful than others in economic terms.

\section{HYPOTHESES}

While research in this area is still at an exploratory stage, the recent literature led to the selection of the following three hypotheses to be tested:

1. Among any given group of enterprises, teams are involved during the creation and early stages of existence of the venture in a relatively high proportion of more than 50 per cent.

2. Entrepreneurial teams differ in their membership, from family members to acquaintances sharing common goals.

Entrepreneurial teams tend, in most cases, to be formed more as the result of unplanned chains of decisions and events than a consequence of careful planning.

3. The success of the team is related to the complementarity of goals, skills, and levels of interest of the team members. The present study does not allow the measurement of preconceived aspects of team balance, such as functional expertise, management skills, decision-making styles or experiencd (2). However, some of these aspects as well as possibly others, should be identifiable from the information provided by current or former entrepreneurial team members.

The complementarity of goals, skills and levels of interest of the members is expected to change over time, as well as the members of the team. However, for the team to remain in existence, a certain balance has to be kept within the team to ensure that it still contributes to the growth of the venture towards attaining its objectives.

\section{METHOD}

\section{INSTRUMENT}

A semi-structured protocol was used to personally interview each subject. Open questions asked for past recollections about the creation of the venture and its further evolution, with respect to the team members or single-owner involvement. Details about the respondents' personal histories were also asked, when relevant to the entrepreneurial literature, such as being a first child or not, having parents self-employed or not. All interviews were audio-taped. A pre-testing of the instrument was conducted in December 1988.

\section{SAMPLE}

The sample under study is a sub-sample of 39 team-member entrepreneurs drawn from a larger sample of 71 respondents randomly selected across central Ontario in 1989, out of a targeted number of 100 respondents from organizations in existence for at least two years. Some of the respondents were involved in the same team and some of them were involved in up to three different businesses they were currently running. All respondents were, at one time of another, part of a team running at least one business on a full-time basis. All interviews were conducted by the researcher.

\section{ANALYSIS}

The quantitative content of each interview was coded for computer processing and analysed with the SPSSX package. The qualitative content was analysed to find commonalities within and across team members' recollections using analysis of content techniques (5) (6) (7). 


\section{SAMPLE DESCRIPTION}

The socio-demographic descriptors of the sample are summarized in Table 1. In relevant cases, a comparison is presented between the group of respondents not involved in a team and the group of team-member respondents. Results are not presented for the first group for variables showing no significant difference between the two groups.

Gender representation in the sample is close to the distribution of the general entrepreneurial population in Canada (21.6 per cent compared to 23.1 per cent of females). The respondents' age is also comparable to national statistics ( 42.1 years as per federal records, compared to 44 years in the sample). The relatively high level of education among the sample also is consistent with national figures, showing entrepreneurs as generally more educated than their counterparts in their age group among the general population.

TABLE 1

\section{SAMPLE DESCRIPTION}

TOTAL SAMPLE: 71 respondents

TEAM SUB-SAMPLE: 39 respondents or $54.9 \%$

\section{(ALL FURTHER STATISTICS ARE ABOUT THE TEAM SUB-SAMPLE UNLESS OTHERWISE INDICATED)}

FEMALE: 9 or $23.1 \%$

MALE: 30 or $76.9 \%$

AVERAGE AGE: 44

About 18 per cent of the respondents were born in a different country than Canada (none in the United States), a lower proportion than the 29 per cent of non-Canadian-born citizen in Canada's general population. The proportion of English-Canadians results in being higher than the general population in this sample, while French-Canadians are underrepresented by three to five percentage points.

\section{TABLE 1 (CONTINUED)}

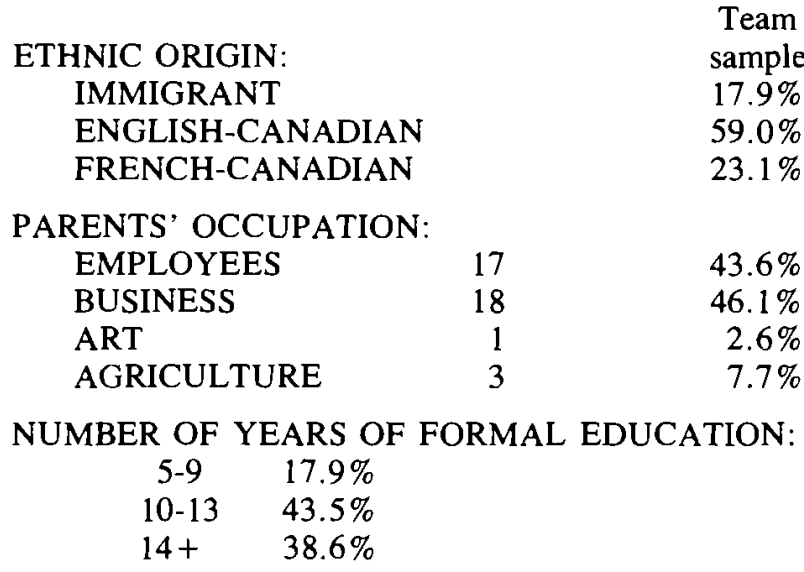

Seventeen respondents from the 39-respondent team-member group had been involved in the creation of more than one business, nine of them having created another business before, three of them having created two businesses, four of them three and one of them six. The total number of businesses created by the sub-sample of 39 people was 54 .

In both groups, about 35 per cent of the respondents were first children; however, 
a major difference appears at the second-child level, where only 25 per cent of the nonteam-member respondents were second children, as compared to 41 per cent of the team members. As a result, proportions for being a third child or more (the average number of children in the family of origin is 4.3 , with numbers ranging up to twelve) are reversed in favor of non-team-member respondents (37.5 per cent compared to 22.1 per cent). Such a result must be taken with the perspective that, according to two of the respondents, being the member of a family with five, eight, or 12 children does not necessarily involve being raised with four, seven or 11 siblings: rather, the children are clustered into sub-groups where a third or fourth child may have to act and react like the first child of a smaller family. Such was the perception expressed by two of the respondents when asked about their rank among children in their family of origin.

\section{TABLE 1 (CONTINUED)}

$\begin{array}{lcccc}\text { RANK IN FAMILY OF ORIGIN: } & \begin{array}{c}\text { First } \\ \text { child }\end{array} & \begin{array}{c}\text { Second } \\ \text { child }\end{array} & \begin{array}{c}\text { Third } \\ \text { child/more }\end{array} & \mathbf{n} \\ \text { Team members } & 35.9 \% & 41.0 \% & 22.1 \% & 39 \\ \text { Other respondents } & 37.5 \% & 25.0 \% & 37.5 \% & 32\end{array}$

NUMBER OF CHILDREN IN FAMILY OF ORIGIN:

$\begin{array}{lr}1 \text { Child } & 7.7 \% \\ 2 \text { Children } & 17.9 \% \\ 3 \text { Children } & 25.6 \% \\ 4 \text { Children } & 5.1 \% \\ 5 \text { Children } & 23.1 \% \\ 6 \text { or more } & 20.5 \%\end{array}$

Average number of children in family of origin: 4.36

NUMBER OF COMPANIES INVOLVED WITH: 1

TOTAL NUMBER OF ORGANIZATIONS INVOLVED IN BY RESPONDENTS: 54

The number of people involved at the creation of the business, as compared to the number involved at the time of the interview shows changes in the teams' composition. This suggests that entrepreneurial teams should not be seen in a static way but, conversely, in their evolutive dynamics.

TABLE 1 (END)

AVERAGE AGE AT CREATION OF FIRST BUSINESS: 26

RANGE: 13 to 51

MEDIAN: 25

$\begin{array}{lcc}\text { NUMBER OF EMPLOYEES } & \text { FULL TIME } & \text { PART-TIME } \\ \text { (Average) } & 22 & 6\end{array}$

NUMBER OF YEARS IN PRESENT BUSINESS: Number of

$\begin{array}{lccc} & \text { Years } & \text { Respondents } \\ & 2-5 & 12 & 30.8 \% \\ & 6-10 & 5 & 12.9 \% \\ \text { Median: } 12 \text { years } & 11-20 & 12 & 30.8 \% \\ & 21+ & 10 & 25.5 \%\end{array}$


NUMBER OF PEOPLE INVOLVED IN THE TEAM: AT CREATION

$\begin{array}{ccc}\text { \# People } & \text { \# Cases } & \text { N } \text { Cases } \\ 1 & 6 & 9 \\ 2 & 25 & 20 \\ 3 & 5 & 7 \\ 4 & 3 & 1 \\ 5 & 0 & 2 \\ & \text { RESULTS } & \end{array}$

\section{TEAMS AS VENTURE INITIATORS}

Hypothesis 1: 50 out of the total sample of 71 respondents were part of a team when creating their first business (70.4 per cent of the cases), thus partly supporting hypothesis 1 . This figure may, however, be inflated by the presence of multiple responses about the same business coming from team respondents. For example, in one case, the three members of a same team were participating in the study. A verification among the total number of companies $(n=107)$ created by the total sample $(n=71$ respondents) over their businsss life confirmed this tendency, as 59 of them ( 55.0 per cent) were created by a team including a minimum of two members. Such a result is consistent with earlier studies (8) (9).

\section{A TYPOLOGY OF ENTREPRENEURIAL TEAMS}

Hypothesis 2: Part A of this hypothesis predicts the existence of different types of entrepreneurial teams. A first examination of the composition of each team led to the distinction of four categories (Table 2), described as follows:

\section{TABLE 2}

ENTREPRENEURIAL TEAM CATEGORIES

Categories of teams:

Husband and Wife (HW)

Family-related (F)

Partners (P)

Short-term partnerings (XP)

Total

$\begin{array}{ccc}\begin{array}{c}\text { Number of teams } \\ \text { in sample }\end{array} & \begin{array}{c}\text { Number of } \\ \text { team members }\end{array} & \begin{array}{c}\text { Number of } \\ \text { respondents }\end{array} \\ 8 & 12 & 13 \\ 6 & 23 & 8 \\ 6 & 14 & 9 \\ 9 & 9 & 9 \\ 29 & 59 & 39\end{array}$

- The Husband-and-Wife (HW) category involves teams where both married or common-law partners make a living from working in the same business. These teams were the easiest to interview fully, (i.e. involving both partners in the study; 13 respondents for eight teams). They tend to be long-term, stable relationships. In this sample, out of eight HW teams, six were married prior to getting into their first business and still are, with an average of 25 years of business experience. Seven out of eight of these teams had started at least two ventures lasting more than two years in existence over their business career. The total number of businesses created by these eight teams equals 20 , an average of 1.25 per member, or 2.5 businesses per team. Totals range from one to five successful start-ups.

- The Family-related teams category $(F)$ groups teams where two or more related people participate in the full-time running of the organization. Usually only one of the team members participated in the interview. These teams also were very long-lasting ones, with an average of 29.5 years in business. However, the distribution is skewed by an older 
respondent and, when removed from the distribution the number of years of business experience averages 23.4 years. Over the six teams, business experience ranges from 13 to 60 years, or 37 years after removal of the highest case. Business venturing is very widespread among this category, with a total of 19 business start-ups, or 0.83 per team member and 3.17 per team, slightly higher than the HW category. Two of the teams interviewed mentioned that a pooling of financial assets and expertise among the family members was a key to the success of their businesses. The total number of start-ups among these teams varies from one to nine. The outlier case mentioned earlier was not distorting the results here.

- The Partners category $(P)$ includes teams running a venture through partnership between non-family related people. The participation of one partner only was mostly the rule for the purpose of the study, except in two cases. An average of 6.8 years of experience in business shows this group as being very young relative to the others. Business experience in this group ranges from two to 17 years. In this category, eight businesses were created so far by the six teams. Comparisons with the previous categories cannot be made due to the differences in business experience. It would be useful to verify:

- (a) Whether such teams are more common among younger business ventures than among "older" ones (25 years-plus);

- (b) How they are formed on a larger-sample scale (at attempt to answer this question is part of the results related to hypothesis $2 \mathrm{~B}$ in this study).

- The Short-term partnering (XP) category comprises people who were the sole owner, or sole manager at the moment of the interview. All were part of a founding team of two or more people at start-up and, later in the life of the business, ended up buying out their partners' shares. While no longer team members, it was felt that their experience could shed some light on the success aspect of entrepreneurial teams. The nine former teams involved in the study included a total of 20 members at creation, or an average of 2.22 members per team. This is comparable to the average of 2.33 members per team among the $\mathrm{P}$ category (The $\mathrm{F}$ category is way above these figures at 3.83 average number of members). The nine respondents in this category have an average of 15.7 years of business experience but, any comparison with the other categories is irrelevant as they have been in business on their own since the time of team breakup. In the (B) part of this hypothesis the breakup circumstances will be categorized as result of the content analysis performed on the interview transcripts.

\section{TEAM FORMATION}

Hypothesis 2B suggests that forming a team is, in most cases, more the result of unplanned chains of decisions and social encounters, than a consequence of careful planning. To verify or invalidate it, the transcripts of the interviews of all respondents from all four categories were examined. As team break-up may also be related to the way a team was formed, we compared, in the XP category, the answers dealing with team formation with those concerning the breakup period (the bias being that the design of this research did not allow the gathering of the "other side" of the story from the partner who had left).

\section{HUSBAND-AND-WIFE TEAM FORMATION}

The circumstances of team formation in the case of HW teams may seem evident. However, results show that marriage was not always related to the team involvement in a business. In four cases, one of the partners got into business first, joined later by the other. In two of these cases, the wife created a business and her husband joined after being laid-off by his employer. In the two others, the husband created a business which grew in need of person of confidence to help managing: the wife quit her job to help at tasks that were complementary to those performed by the husband. 
The four remaining cases involved both husband and wife at the moment of creation of the business. However, some particular event in the life of one of the persons led to the start-up in almost all cases: in three cases the husband had had to quit his job because of firing or lay-off, and, in the fourth case, an opportunity came up where both husband and wife had to be involved to ensure the success of the venture. In one case, the wife kept a full-time job and, at the same time, actively participated in the creation and management of four businesses, two of them still being in operation at the time of the interview.

\section{FAMILY-RELATED TEAM FORMATION}

The formation of $F$ teams is related to the family ties that evolve over time. Of the six cases identified, two were involving brothers, later joined by other brothers who either quit jobs or were laid-off (one case only) at one time. The four other cases involved the father teaming-up with relatives: brothers-in-law (one case, they quit the company after a few years); his sons (two cases); his mother (one case). In two of the teams the number of members remained the same but the people involved changed: the wife replaced the mother, the sons and grand-sons got involved as they grew up and finished their education. In other cases, the team grew with the further involvement of more close relatives, both children and children-in-law. All respondents stressed the importance of family commitment towards the business and projected strong values of independence and desire to remain self-employed. For most of the children team-members interviewed, being part of the business is considered as a way of achieving both personal and family goals, even at the cost of renouncing the pursuit of a promising career in employment (as a chartered accountant or senior executive in some cases).

The creation of the business in itself is generally described as the result of two factors: a previous interest in the field which led the team to seek and discuss opportunities in the sector of interest over a period of time prior to creation (often several years); a sudden discovery of a promising opportunity by one of the founding team members which led to the agreement among them that the time had come to act.

\section{FORMING PARTNERS TEAMS}

The sample contains six $P$ teams. In three of the cases the team went into business out of dissatisfaction with its members' position at the time. Business venturing in a sector already well-known became an opportunity in itself. In all cases the partners had known each other for several years and had previously worked together. In the three cases, business venturing appears as part of the personal growth of the partners more than a desire to pursue a lucrative economic activity.

The three remaining cases exemplify three different types of situations: In the first case, this entrepreneur's children were not interested in the business and retirement being contemplated at a later stage, so he decided to take an employee as a partner to groom him for the business. Another situation involves a skilled husband-and-wife team joining with a partner for both financial and management reasons. In the third case, the threepeople team involves two previous partners and a former employee, with the scope of getting into multiple businesses in the future, leaving the new partner with the managerial role in the company. In all cases, as previously stated, the partners had known and worked with each other beforehand.

\section{WHEN SUCCESS MEANS NO-TEAM}

Out of the 29 teams originally formed in the sample, nine had broken up by the time of the interview. Were they formed differently than the others and when, how and why did 
they break up? As in previous categories, team members knew each other well prior to entering the business. Four respondents described the partnership in terms of division of tasks (one in the shop, the other in the office), instead of goal sharing (more often the case among the $\mathrm{P}$ category). The others explained the formation of the team by the fact that they were friends or knew each other. In all cases, whether the attitude existed or not at the time, there is a lack of expression of a common goal. The bind between partners is always expressed in instrumental ways: the partner took charge of the office, was a skilled designer and was good at production. In one case the two partners were described as friends.

Breakup occurred in two time periods: either within five years into the venture, or after 10 or more years. The average breakup year is the eighth year, excluding the situation where a partner died by accident. Five of the partnerships broke off within five years; in these cases the departure of the partner is described as due to lack of interest in the business. The later retirements are situations where the partner who was leaving either wished to retire or had decided to seize a new business opportunity. One breakup after seven years was described as the result of difficulties working together.

\section{COMPLEMENTARITY AND SUCCESS}

Hypothesis 3 suggests that successful, or lasting teams are able to mix common goals with complementary task performance within the venture. It is interesting to notice that the XP (Short-term-partnering) category of respondents described their former teams mostly in terms of tasks performed. They also, in five cases out of nine, divided tasks between production and office work (the sectors involved are manufacturing of parts and design); in these cases, the office manager left and the shop manager remained as sole owner.

The three other types of teams mostly described themselves in terms of the goals of the business but insisted upon the division of tasks between members. In the HW category, the separation of tasks was clear in all cases, always involving a different work location for each member (one in the kitchen, the other in the restaurant; one doing lab work, the other dealing with customers, and the like). The F category also described a clear-cut division of tasks situation, while the $P$ team members insisted less on that aspect and more on long-term goals. They often tended to perform similar tasks at different hours during the day, or within different businesses. In conclusion, this hypothesis is supported fully for the family-type categories, but much less for the $\mathrm{P}$ and XP categories of teams.

\section{DISCUSSION}

The results of this study uncover the existence of different types of entrepreneurial teams. Such a perspective is adding another facet to the development of a theory of entrepreneurial decision-making and performance. Most of the studies are concentrating on the CEO, or the individual entrepreneur, thus neglecting the social fabric around the person. Woo, Cooper and Dunkelberg (10) warned against easy interpretations of entrepreneurial types, such as Smith's (11) craftsmen/opportunists dichotomy, while Davidsson (12) tended to accept the usefulness of the typology. The study of entrepreneurial teams as social phenomena has to go through a stage where some order is made out of the existing chaos; however, sight should not be lost of the ultimate objective which is to increase the proportion of the population involved in starting up and running competitive and profitable businesses.

The team formation process described earlier suggests that a large amount of information is discussed and internalized among team members prior to any type of decisionmaking. A majority of the respondents stressed their experience of a long incubatory period before they started a first business, particularly when coming from an employee social background. Those respondents coming from entrepreneurial families tended to enter the 
business world out of family habit, even if most of them tried employment at least once. However, all types of teams appear to react more through team work to environmental pressure than through lone entrepreneurial reactions.

\section{POLICY IMPLICATIONS}

The most important implication of this study is that entrepreneurial teams represent a very powerful source of business and job creation, particularly when involving a group of family members. It also is cautiously suggested that partnerships between unrelated people may often be short-lived due to a number of factors which are difficult to fully describe at this stage. However, the reasons for team building contribute to the success of the venture, whether the team is going to survive or not. In other words, the ventures started by later unsuccessful teams became winners under a sole proprietorship. Finally, the high proportion of businesses started by teams in the total sample shows their importance as compared to the "lone entrepreneur" myth

\section{LIMITS OF THE STUDY AND IMPLICATIONS FOR FURTHER RESEARCH}

While the population of Central Ontario is considered as representative of Canada as a whole and often used as a national brand test market, its economic fabric of service and base industries tends to bias the results obtained. The other source of bias is the small size of the sub-samples obtained when trying to categorize cases. Further projects should examine these categories in more detail. The bias resulting from memory distortions after a number of years is spread among the whole sample. As Ricoeur (13) puts it, what really counts is not what exactly happened, but how the story (the myth of creation) is told. In the entrepreneurial firm, the entrepreneurs' past recollection are often the mold for their future strategies and their outlook on the world.

The methodology used here allowed a number of categorizations which may not be discovered when using paper-and-pencil questionnaires subject to strictly quantitative analysis. As this study mostly dealt with social facts, some of them from a distant past, content analysis from in-depth, semi-structured interviews was an appropriate way to gather data, common to the sociological field. A move in this direction appears appropriate in order to better understand the complex social aspects of entrepreneurship.

\section{REFERENCES}

1. Kamm, J., J.C. Shuman, and J.A. Seeger, (1988), "The costs and problems of assembling the entrepreneurial team", Presented at the Babson College Entrepreneurship Research Conference, University of Calgary.

2. Kamm, J., et al. (1989) "Are well-balanced entrepreneurial teams more successful?" Presented at the Babson College Entrepreneurship Research conference, St. Louis University.

3. Carland, J.W. et al. (1984), "Differentiating entrepreneurs from small business owners: A conceptualization", Academy of Management Review, 9, 2, 354-359.

4. Olson, P.D. (1987), "Entrepreneurship and management", Journal of Small Business Management, July 7-13.

5. Pool, I. de S., ed. (1959), Trends in content analysis, Urbana, Il: Illinois University Press.

6. Holsti, O.R. (1969) Content Analysis for the Social Sciences and Humanities, Reading, MA: Addison-Wesley 
7. Bardin, L. (1977) L'Analyse de contenu, Paris: P.U.F.

8. Cooper, A.C., (1973), "Technical entrepreneurship: What do we know?" $R \& D$ Management, 3, 2, 59-64.

9. Teach, R.D., F.A. Tarpley, and R.G. Schwartz, (1986), "Software venture teams, Frontiers of Entrepreneurship Research, Wellesley, MA: Babson College.

10. Woo, C.Y., A.C. Cooper and W.C. Dunkelberg (1988), "Entrepreneurial typologies: Definitions and implications", in B.A. Kirchhoff et al. Eds.) Frontiers of Entrepreneurship Research 1988, Wellesley, MA: Babson College, 165-176. 